\title{
OS FILHOS DA LEI
}

\section{Gizlene Neder e Gisálio Cerqueira Filho}

Este artigo enfoca a história das idéias jurídicas, tendo como referência a questão do poder e da disciplina sobre a família, instituição-chave no leque das práticas de controle e disciplinamento social, na passagem à modernidade. Analisamos principalmente o ideário político (e jurídico) erigido em torno dos acalorados debates ocorridos desde fins do século XVIII em Portugal e na conjuntura de emancipação política no Brasil (1822), quando se alardeou a intenção de instituir um código criminal e outro civil modernos.

O trabalho contempla duas ordens de questão. Num primeiro plano, situa o processo de circulação das idéias iluministas no campo do Direito, tendo em vista a relação centro/periferia no que se refere aos lugares de produção destas idéias. Em segundo lugar, enfoca o pátrio poder e a situação da mulher e dos filhos-família, ao lado

* Este artigo insere-se em projeto integrado de pesquisa intitulado Poder, Idéias Jurídicas e Autoridade na Família: História, Direito e Ideologia em Portugal e no Brasil, patrocinado pelo Conselho Nacional de Desenvolvimento Científico e Tecnológico (CNPq). Para o desenvolvimento da pesquisa contamos também com Bolsa de Investigação da Biblioteca Nacional de Lisboa/Fundação Luso-Brasileira para o Desenvolvimento do Mundo de Língua Portuguesa. da discussão sobre o casamento civil, que acompanhou o processo de secularização e modernização em Portugal e no Brasil. Tal questão parece ter se constituído na pedra de toque da resistência conservadora que dificultou e atrasou as reformas.

\section{Centro e periferia: a circulação de idéias}

Estamos particularmente interessados em mapear as situações de apropriação cultural vis-àvis a identificação do percurso do iluminismo jurídico, que propõe reformas nos códigos legais desde fins do século XVIII. As propostas dos reformadores implicaram uma luta ideológica que envolveu diferentes campos de força política.

Trabalhamos a relação do pensamento e da cultura jurídica luso-brasileiros com os centros de produção de idéias europeus mais significativos em fins do século XVIII (Itália, França e Holanda ${ }^{1}$ - a Europa apresenta, então, uma dinâmica histórico-ideológica policêntrica), levando em conta a existência, na época, de um vasto processo de circulação de idéias que acompanhou a circulação de pessoas, mercadorias etc. não somente no território europeu, mas também em seus prolonga- 
mentos ultramarinos. De modo que a origem das idéias (ou seja, o lugar das idéias), a autenticidade e o mimetismo (em Portugal e no Brasil) são temas que definem a pauta desta discussão.

Tanto em Portugal quanto no Brasil, o ímpeto reformador que acompanhou a passagem à modernidade estabeleceu um diálogo com as principais correntes de pensamento no resto da Europa. A introdução do paradigma legalista, que toma o primado da lei como eixo da articulação do campo político e ideológico, anunciava, na virada do século XVIII para o XIX, a necessidade de adotar códigos criminal e civil modernos, o que significava ir muito além da mera introdução de princípios constitucionalistas que visassem à limitação dos poderes absolutistas das monarquias européias e relacionava-se ao processo de secularização em curso. Nos dois países, encontramos a defesa da necessidade da reforma na codificação.

Em Portugal, observa-se uma movimentação expressiva que partiu, num primeiro momento, da própria monarquia. No reinado de D. Maria I, na esteira da reforma pombalina do ensino jurídico (1772) que propiciou a formação intelectual iluminista, foram encomendados dois projetos de códigos ao jurista Pascoal José de Mello Freire: um de direito público e outro de direito criminal. ${ }^{2} \mathrm{O}$ jurisconsulto coimbrense preparou, ainda em fins do século XVIII, um terceiro projeto de reforma, do Regimento do Santo Ofício, desta vez sob a encomenda do arcebispo inquisidor-geral. ${ }^{3}$ Nenhum dos projetos redigidos por Pascoal de Mello Freire foi aprovado. Portugal só veio a ter uma nova codificação criminal e civil em meados do século XIX (1852 e 1867, respectivamente).

Leitora de Bentham e Voltaire, dentre outros, a intelectualidade portuguesa mostrou preocupações com a reforma política e jurídica do império luso-brasileiro. No escopo teórico mais geral do Iluminismo, os juristas convergiam no cuidado com as referências a autores e livros. Aderiram superficialmente ao ímpeto reformador do centro hegemônico do pensamento europeu que, na Itália e na Holanda com Beccaria, Grocius e Puffendorf, abria caminho para a reforma do código criminal. Sobretudo os dois últimos autores foram muito referidos, tanto pelos juristas portugueses quanto pelos brasileiros, formados em Coimbra. Afinal, foi a formação coimbrense que embasou a primeira geração de homens públicos que assumiu a direção política da sociedade brasileira a partir da emancipação política. Da França, os ventos da modernidade sopraram anunciando as reformas sobretudo do código civil. Residia neste ponto o grande pólo de resistência política, ideológica e afetiva às mudanças entre os juristas luso-brasileiros, uma vez que a nova concepção de direito de família, erigida no bojo do processo revolucionário francês, implicava uma visão secularizada do casamento, admitindo-se o divórcio. O código civil francês (de 1804, mais conhecido como Código Napoleônico) esteve, ao longo de todo o século XIX, no centro da polarização ideológica que dividiu, apaixonadamente, o universo político dos juristas.

No Brasil, o movimento pela independência que culminou com a emancipação política em 1822 evocou igualmente a necessidade de se fazer um código civil e outro criminal para a jovem nação emergente. Em 1830 foi aprovado o Código Criminal. Uma leitura atenta deste código revela uma presença forte do projeto de código criminal encomendado à Pascoal José de Mello Freire em fins do século XVIII, ao lado das idéias do iluminismo penal inspirado em Beccaria e Bentham (Neder, 2000). Quanto ao código civil, o país esperou quase um século mais. Somente em 1916 foi aprovado o Código Civil Brasileiro, tendo as Ordenações Filipinas (de 1603) vigorado para o direito de família até esta data - portanto, 94 anos após a emancipação política (1822) e 27 anos após a proclamação da República (1889). Assim, estamos diante de uma situação histórica em que ruptura (emancipação política, elaboração de novo código criminal, mudança de regime político de monarquia para república etc.) e continuidade (permanência das Ordenações para o direito de família além de sua vigência em Portugal) alternam-se de forma pendular. A relação centro/periferia adquire uma complexidade ímpar, de acordo com o prisma enfocado. Onde o centro: Itália, Holanda ou Portugal?

Grosso modo, tomamos como referência as fortes ligações existentes entre o pensamento polí- 
tico português e o brasileiro no período considerado. E quando pensamos a relação centro/periferia na temática do iluminismo jurídico, estamos nos referindo a uma só formação histórico-ideológica luso-brasileira e sua relação com os vários centros de produção de idéias iluministas europeus acima mencionados. Sobretudo, tomamos por base a constituição de um projeto de construção de império (luso-brasileiro) elaborado por um segmento da intelectualidade influenciada pela orientação política pombalina (Neves, 1998) e seu projeto de modernização conservadora. Neste projeto, as atualizações históricas foram empreendidas de forma a garantir a inserção da formação histórica no quadro mais geral do mercado mundial, sem que a estrutura social (fortemente hierarquizada) e a visão de mundo tomista tenham sido alteradas.

Desnecessário ressaltar a enorme importância de que se revestem estes temas nos dias de hoje, tendo em vista a discussão e elaboração de uma nova codificação civil para o Brasil nesta virada de milênio. Em que medida o atraso na aprovação do código civil é um sintoma de permanências de uma cultura política (e jurídica) fortemente assentada em concepções tomistas e absolutistas sobre o poder, a hierarquia e a obediência? De que forma a extensão do pátrio poder, tal como o formulado nas Ordenações do Reino, perpetua um modelo de família holístico, extenso, onde o paterfamilis é plenipotente e a idéia de indivíduo é muito tênue? Quais as implicações desta estrutura de família quanto aos direitos da mulher e dos filhos-família (sucessão, dote, emancipação etc.)? Por fim, de que forma esta estrutura afetou (afeta ainda) a condição feminina e o modelo institucional de assistência aos órfãos e outras crianças que se encontram no que hoje chamamos "situação de risco"? Mais: o desdém para com a vida e as práticas de genocídio associadas ao extermínio, mormente contra os afro-brasileiros, não estariam ancorados no absolutismo onipotente deste paterfamilis e numa reiterada ausência da função parental do Estado? Estamos convencidos de que vários dos problemas que vivenciamos hoje no campo das políticas públicas voltadas para atendimento de crianças e adolescentes (prostituição infantil, abuso sexual, estupro, violência doméstica, abando- no) não podem ser solucionados sem que tenhamos clareza do processo histórico-cultural subjacente. Podemos afirmar, ainda, que o fracasso das políticas públicas para o atendimento de crianças e adolescentes, de velhos e doentes mentais, nestes mais de cem anos de ordem republicana (seja no campo assistencial, judicial, policial, ou educacional) deve-se, em boa parte, à forma tímida como o Estado (paradoxalmente, no mais das vezes, forte e autoritário) se incumbe de sua função parental (Legendre, 1983 e 1992). Queremos com isto dizer que, em alguma medida, a cultura política no Brasil dá suporte ideológico ao paterfamilis, que, todopoderoso no texto da lei jurídica (Cerqueira Filho, 1993), ${ }^{4}$ açambarca sob as abas de seu chapéu uma parentela extensa (mulher, filhos, parentes, afilhados, criados e agregados), produzindo, para além dos efeitos macropolíticos já bastante enfocados pelos estudos no campo da Ciência Política (Oliveira Vianna, 1974), ${ }^{5}$ efeitos ideológicos e políticos que obstam a institucionalização e a profissionalização de políticas públicas eficazes. Em outras palavras, os asilos (de alienados, de velhos), os orfanatos, as prisões (inclusive para jovens infratores) — bem como o sistema de educação pública — não atuam em sua plenitude de forma a garantir o suporte ideológico necessário para o exercício da função parental do Estado.

\section{Direito de família: ruptura e continuidade}

As formações sociais portuguesa e brasileira apresentam fortes vinculações ideológicas e afetivas que pontuam especificidades na passagem à modernidade. Embora a inserção destas formações sociais no mercado internacional implique modernização e atualização histórica, mediante a ruptura com a mentalidade política e jurídica previamente dominante, o conservadorismo clerical tem atuado produzindo efeitos psicológicos, políticos e até jurídicos de continuidade das concepções tomistas. Os estudos sobre o controle social e a disciplina enfocando a questão da instituição familiar, vista como parte das tecnologias de controle social, constituem campo de observação privilegiado deste processo. 
A proposta de reforma da codificação penal, surgida primeiramente na Itália com Beccaria (século XVIII), a introdução do revolucionário código civil francês (1804), que propôs o casamento civil, e, posteriormente, o código civil alemão (1897), muito referido pelos juristas brasileiros da área de direito de família, implicaram um debate no qual a circulação das idéias jurídicas pode ser facilmente detectada.

Sobretudo, devemos levar em conta a aceitação ou não da idéia de indivíduo na formação histórica brasileira na passagem à modernidade (tal como na Europa) e sua incorporação, tendo em vista a autoridade do Estado e da família (pátrio poder), no direito civil brasileiro. Simultaneamente, é importante ver como as formas de controle e disciplinamento social mudaram, ou não, tomando-se como referência o pensamento jurídico e a instituição familiar.

Especialmente em relação ao pensamento jurídico, identificamos um conjunto de fantasias absolutistas de um controle social absoluto como expressão de permanências de uma cultura jurídico-política bastante antiga. A penetração de propostas iluministas não foi suficiente para alterar de forma expressiva a organização social e política que fundamentava as práticas jurídicas em Portugal e no Brasil (Neder, 1996). A visão de mundo tomista, espraiada na Península pela prática política e ideológica da Igreja Romana, sustentava uma concepção de sociedade rigidamente hierarquizada, produzindo efeitos de permanência cultural de longa duração, com fortes desdobramentos para os afetos e as emoções presentes nas formações históricas portuguesa e brasileira (Cerqueira Filho e Neder, 1997), que resistem, ainda hoje, ao corolário das tantas mudanças promovidas pelas concepções iluministas e liberais sobre os direitos.

Empreendemos a identificação destas permanências através da análise das metáforas/metonímias, das condensações/deslocamentos, tomados aqui como sintoma/indício a revelar afetos e emoções, muitas vezes inconscientes. O historiador italiano Carlo Ginzburg (1991) propõe um método heurístico centrado nos dados marginais, nos detalhes $\mathrm{e}$ nos resíduos, que, manifestados involuntariamente, permitem ao analista procedimentos interpretativos significativos, que aplicamos com desdobramentos para o campo das emoções e afetos (Cerqueira Filho e Neder, 1997). Nossa abordagem metodológica é heterodoxa. De um lado estamos adotando o método indiciário e a idéia de sintoma, combinadamente e de forma ampliada com o enfoque psicanalítico; de outro, não estamos nos prendendo rigidamente à concepção de cultura e permanência cultural adotada pelo historiador italiano (ancorada no estruturalismo lévi-straussiano), uma vez que estamos considerando o processo de apropriação cultural a partir de uma perspectiva dinamista.

O projeto político republicano, tanto no Brasil (1889) quanto em Portugal (1910), pombalinamente, possibilitou um conjunto de modernizações, separando a Igreja do Estado. Entretanto, encontramos evidências de uma continuidade psicológica e ideológica que garante a prática autoritária de controle social, com ênfase numa dogmática jurídico-penal em detrimento de procedimentos disciplinares aplicados pela Criminologia, que poderiam abarcar, interdisciplinarmente, algumas questões suscitadas pela Sociologia, pela Antropologia e pela Psicologia e a Psicanálise. No campo do direito de família (direito civil), as permanências e a continuidade são mais evidentes, uma vez que sua mera discussão tem implicado considerações psico-afetivas nevrálgicas para o conservadorismo clerical das duas formações históricas. Os desdobramentos deste processo num século XX republicano têm sido observados na grande dificuldade de alteração dos estatutos jurídicos do direito de família, ou nos grandes obstáculos encontrados pelos positivistas republicanos, no Brasil, por exemplo, para a implementação de uma política educacional pública. As pressões da Igreja contra a escola pública de tempo integral, por exemplo, não podem ser vistas, no nosso entender, tão-somente como preservação de seus interesses econômicos, por deterem uma rede grande de escolas confessionais. O núcleo cultural e ideológico desta resistência a políticas públicas educacionais e beneficentes está fortemente imbuído da idéia de família tridentina, enquanto projeto civilizador da Igreja, e constitui a base afetiva das lutas ideológicas que emperram as políticas públicas nestes setores (Neder, 1994). 
Pensamos que, neste final de milênio, a educação e a formação profissional de operadores sociais eficientes (médicos, juízes, promotores, policiais, professores, assistentes sociais etc.) terão de ser tomadas como referência estratégica primordial para o desenvolvimento social. Os operadores sociais devem saber lidar, política e ideologicamente, com estas permanências histórico-culturais.

Consideramos o pensamento jurídico português como uma matriz (Faoro, 1975) muito mais no sentido de uma permanência cultural (cultura jurídica), um substrato, do que propriamente "fonte inspiradora" do pensamento jurídico e político brasileiro. A inspiração encontrava-se no pensamento jurídico liberal tout court, em termos da aparência e das preferências temáticas e ideológicas.

Esta a razão, no nosso entender, de uma certa forma de atualização histórica que encaminha a passagem à modernidade com traços autoritários. Incorporam-se aspectos institucionais da modernização, com inflexões em algumas idéias liberais, a partir de uma leitura conservadora das reformas empreendidas (Neder, 1996). As reformas pombalinas da segunda metade do século XVIII inscrevem-se neste quadro. Sua fórmula de atualização histórica (calcada no pragmatismo político) está ainda a influir nos processos de modernização de Portugal e do Brasil (Faoro, 1975 e 1994).

Um dos sintomas desta influência é a forma como o pensamento jurídico no Brasil (e em Portugal) lida com as relações entre a idéia de indivíduo, desenvolvida a partir da passagem à modernidade (e que está presente nas leis civis francesas), e a delicada questão do pátrio poder, presente na codificação portuguesa (Ordenações Filipinas) adotada no Brasil, como já ressaltamos, até a promulgação do Código Civil Brasileiro (1916). Sublinhe-se, ainda, que as Ordenações do Reino de Portugal - sucessivamente, as Ordenações Afonsinas (1446-47), as Ordenações Manuelinas (1512-1514) e, por fim, as Filipinas (1603) constituem um mesmo corpus juris. Portanto, as Ordenações Filipinas, de início do século XVII, que têm no código do século XV sua formulação básica (Silva, 1985), vigoraram no Brasil por muito mais tempo que em Portugal no que se refere ao direito de família.

\section{Circulação das idéias iluministas e as reformas no campo do Direito}

O estudo sobre circulação de idéias situa-se, historicamente, na discussão sobre a reforma dos códigos civil e criminal brasileiros, que se arrasta praticamente desde a emancipação política, quando a necessidade de sua formulação foi aventada. Passa pela encomenda, por parte do Imperador, de um projeto de lei a Augusto Teixeira de Freitas, na década de 1850, e culmina, na outra ponta deste processo, com um acirrado debate na virada do século XIX para oXX, quando outra encomenda de projeto é feita pelo governo republicano ao jurista Clovis Bevilacqua, que teve como principal interlocutor Rui Barbosa.

O detalhamento deste processo pode clarear nossas referências identitárias dos pontos-chave para a discussão atual sobre a reforma (novamente) da codificação civil brasileira. Em que medida a aludida influência do Código Civil Alemão teria moldado o Código Civil Brasileiro? Onde estaria a também muito aludida tendência ao individualismo (influência francesa?) da codificação brasileira formulada por Clovis Bevilacqua?

De fato, na passagem do século XVIII para o XIX, tanto em Portugal quanto no Brasil, abriram-se discussões sobre estas questões. A modernização da codificação francesa pressionou ideologicamente para que as alterações fossem difundidas. A resistência do conservadorismo clerical (nas duas formações históricas estudadas, Portugal e Brasil) satanizou os ventos da modernidade; os juristas esgrimiram seus argumentos em torno, sobretudo, da legitimação do casamento civil. Portanto, além das legislações dos dois países, contamos com uma vasta fonte documental constituída de teses, livros, artigos e panfletos produzidos no bojo desta discussão.

A continuidade das concepções tomistas pode ser constatada no conservadorismo clerical presente na obra do jurista brasileiro Francisco José Viveiros de Castro, Delitos contra a honra da mulher, ou em Estudos sobre o casamento civil, do jurista e historiador português Alexandre Herculano. O primeiro é um tratado jurídico onde se discute uma tese sobre os delitos de adultério e de estupro. O segundo marca, política e ideologicamente, a posi- 
ção do conservadorismo clerical diante do debate sobre o casamento civil em Portugal em meados do Novecentos.

Destaque pode ser dado a alguns aspectos do livro Delitos contra a honra da mulher (Viveiros de Castro, 1897), que trata de estupro e defloramento. De um lado, do ponto de vista do conteúdo, o livro indica as rupturas com o pensamento jurídico prémoderno (pela adesão do autor ao Iluminismo ao tratar dos delitos contra a mulher). De outro lado, confirma a continuidade de um conjunto de práticas ideológicas inculcadas por séculos de hegemonia do pensamento religioso (e do Direito Canônico) na cristandade ocidental. A mulher que é violentada, por exemplo, é vista não como vítima mas como ré. Ela é considerada responsável pelo estupro, pois se este se deu fora do lar, significa que a mulher expôs-se ao mal (na rua, lugar fora do espaço doméstico/familiar), possibilitando a exteriorização do mal que só ela possui - a sedução. Destarte, ela é responsabilizada pelo delito que sofreu. Interessante observar que, a par da utilização de uma linguagem jurídica moderna para analisar os delitos contra as mulheres (o tema estava na pauta das discussões na França), sobretudo aqueles diretamente dirigidos contra seus corpos (estupro e sedução), este livro mostra-se envolto por um emaranhado ideológico em que os preconceitos do conservadorismo clerical, que veiculam uma imagem da mulher negativa, depreciativa e misógina, manifestam-se vivamente.

Já o texto de Alexandre Herculano (1866) tem um conteúdo panfletário mais explícito, na luta contra a introdução do casamento civil em Portugal. A defesa do casamento como um sacramento, cujos laços indissolúveis devem ser mantidos e estendidos, na legislação portuguesa, para os não-católicos, é o cerne da argumentação de Herculano. Toda a legitimidade do casamento (e conseqüentemente da filiação — legítima —, da herança e da sucessão) deveria permanecer sob o controle político e ideológico da Igreja. Alexandre Herculano fez parte da Comissão Revisora do Projeto de Código Civil Português, elaborado pelo Visconde de Seabra, onde argumentou contra a proposta de secularização do casamento, vitoriosa na comissão por três votos favoráveis contra dois contrários - um deles o de Heculano. Este panfleto constitui um libelo de indignação para tornar pública sua oposição ao projeto aprovado pela maioria da comissão (Seabra, 1866). ${ }^{6}$

O emolduramento das práticas de controle e disciplina, destarte, deve ser buscado na Igreja e em sua forte influência na cristandade européia. Se Michel Foucault (1978) situa o nascimento da prisão nas casas de correção, no século XVI, seu amigo Philippe Ariès (1978) sublinha a importância do Concílio de Trento (1545-1563) na definição de uma estratégia civilizatória da Igreja Romana, tendo em vista a delimitação de um modelo de família e de padrões de controle do comportamento social e sexual.

Os desdobramentos da questão jurídica a partir de uma consideração mais ampla das questões relativas ao controle e à disciplina, fora da prisão, foram apontados por Michel Foucault e Arlette Farge $(1982)^{7}$ e Pierre Legendre (1988). As sutilezas dos micropoderes insinuados através da "docilidade dos corpos", a arte das distribuições, através dos colégios, quartéis, do controle dos horários, vigilância hierárquica, jogo do olhar e tantas outras tecnologias de controle lançam-nos, de um lado, à rua, e ao controle do espaço urbano pela polícia. De outro lado, somos também convidados a refletir sobre estas mesmas questões sob quatro paredes: a institucionalização jurídica da família na passagemà modernidade (Burguière e Segalen, 1998).

$\mathrm{O}$ atraso na modificação do código civil no Brasil deve-se às dificuldades encontradas pelos reformadores do campo jurídico em articular as restrições que a visão moderna de direitos da pessoa (eivada de individualismo) impôs ao pátrio poder, que no Brasil se manteve fundado numa concepção ainda medieval sobre autoridade na família.

As dificuldades de Augusto Teixeira de Freitas, autor do primeiro projeto de código civil para o Brasil, não ficaram longe do quadro acima analisado. As concepções modernas no campo do direito de família tinham no individualismo do Código Napoleônico sua base primeira de sustentação. Junto com a expansão napoleônica pela Europa na virada do século XVIII para o XIX, ocorreu uma grande expansão do ideário revolucionário que forçou o processo de secularização, mesmo em 
formações sociais fortemente controladas pela Igreja, como era o caso de Portugal (e Brasil), Espanha e Itália. ${ }^{8}$ De outro lado, havia os obstáculos de ordem emocional e afetivo-religiosos: Augusto Teixeira de Freitas tinha uma enorme dificuldade de aceitar a idéia de casamento fora do controle da Igreja. Evidentemente, não estamos deixando de considerar outros obstáculos e dificuldades que levaram seu empreendimento ao fracasso, já exaustivamente apontados pelos autores do campo do Direito no Brasil, relacionados à sua oposição à escravidão. No entanto, consideramos estes obstáculos afetivoreligiosos como mais decisivos para o fracasso do primeiro projeto de código civil no Brasil.

Procedendo a um levantamento quantitativo acerca do país de origem das referências bibliográficas contidas no Esboço de Código Civil (Quadro 1 e Gráfico 1), de Augusto Teixeira de Freitas, podemos inferir algumas questões significativas.

\section{Quadro 1}

Obras Citadas por Augusto Teixeira de Freitas, com Repetição de Obras Citadas

\begin{tabular}{lcc}
\hline País & Citações & $\%$ \\
\hline Alemanha & 43 & 19,63 \\
Brasil & 18 & 8,21 \\
França & 132 & 60,27 \\
Portugal & 7 & 3,19 \\
Itália & 12 & 5,47 \\
Outros & 7 & 3,19 \\
Total & 219 & 100 \\
\hline
\end{tabular}

Fonte: Esboço de Código Civil. Rio de Janeiro, Ministério da Justiça e Negócios Interiores, 1852. 8 vols.

Primeiramente, encontramos um leque de referências bibliográficas bastante restrito (um total de 106 obras), com a remissão exaustiva a umas tantas obras, como o Traité du droit Romain de Von Savigny. De outro lado, há um conjunto expressivo de referências a códigos e leis, no mais fino estilo dos comentários jurídicos pré-modernos.

Retiradas as citações repetidas, teremos um quadro bastante próximo se considerarmos as obras procedentes sobretudo da França - 60,27\% (Quadro 1 e Gráfico 1) e 64,7\% (Quadro 2 e Gráfico 2). Porém, encontramos uma diferença significativa nos dados referentes à Alemanha: o percentual de 19,63\% cai para 9,8\% dada a exaustiva repetição nas citações a Von Savigny, o mais romanizado e ocidental dos juristas alemães na época. A obra de Savigny chegou a Portugal e ao Brasil pela tradução francesa.

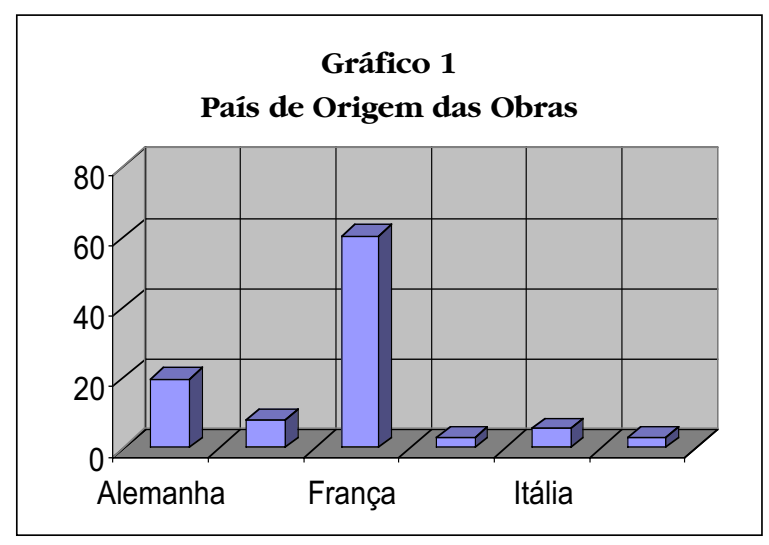

Quadro 2

Obras Citadas por Augusto Teixeira de Freitas, sem Repetição de Obras Citadas

\begin{tabular}{lcc}
\hline País & Citações & $\%$ \\
\hline Alemanha & 10 & 9,8 \\
Brasil & 7 & 6,86 \\
França & 66 & 64,7 \\
Itália & 9 & 8,82 \\
Portugal & 5 & 4,9 \\
Outros & 5 & 4,9 \\
Total & 102 & 100 \\
\hline
\end{tabular}

Fonte: Esboço de Código Civil. Rio de Janeiro, Ministério da Justiça e Negócios Interiores, 1852. 8 vols.

\section{Gráfico 2}

País de Origem das Obras

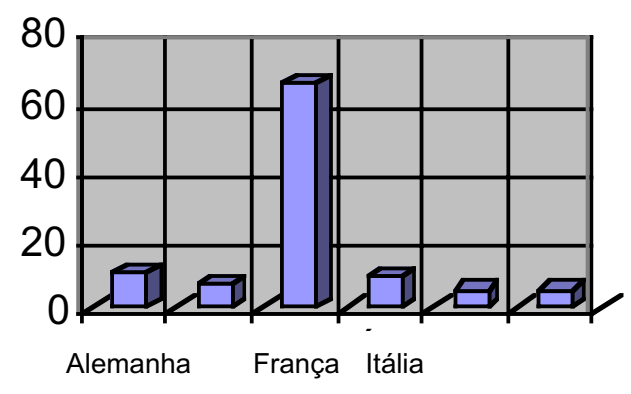


Diferentemente, o quadro de referências bibliográficas contidas nas notas de rodapé do Código Civil Brasileiro (Quadro 3 e Gráfico 3), de Clovis Bevilacqua, meio século adiante, expõe a variedade, a riqueza e a abertura ideológica e política do autor. Atente-se para o fato de que a porcentagem de citações de obras oriundas do iluminismo jurídico francês no campo do direito de família é superior à de qualquer outro centro de produção de idéias, sendo apenas inferior às referências nacionais.

\section{Quadro 3}

Referências Bibliográficas Código Civil Brasileiro

\begin{tabular}{lcc}
\hline País & Número de citações & $\%$ \\
\hline Alemanha & 102 & 10,82 \\
Argentina & 21 & 2,22 \\
Brasil & 414 & 43,94 \\
Colômbia & 7 & 0,74 \\
Espanha & 24 & 2,54 \\
EUA & 14 & 1,48 \\
França & 228 & 24,2 \\
Inglaterra & 9 & 0,95 \\
Itália & 71 & 7,53 \\
Portugal & 30 & 3,1 \\
Suíça & 8 & 0,84 \\
Outros & 12 & 1,27 \\
Total & 942 & 100 \\
\hline
\end{tabular}

Fonte: Clovis Bevilacqua, Código Civil dos Estados Unidos do Brasil. Edição histórica, 2 vols. Ed. Rio, 1977.

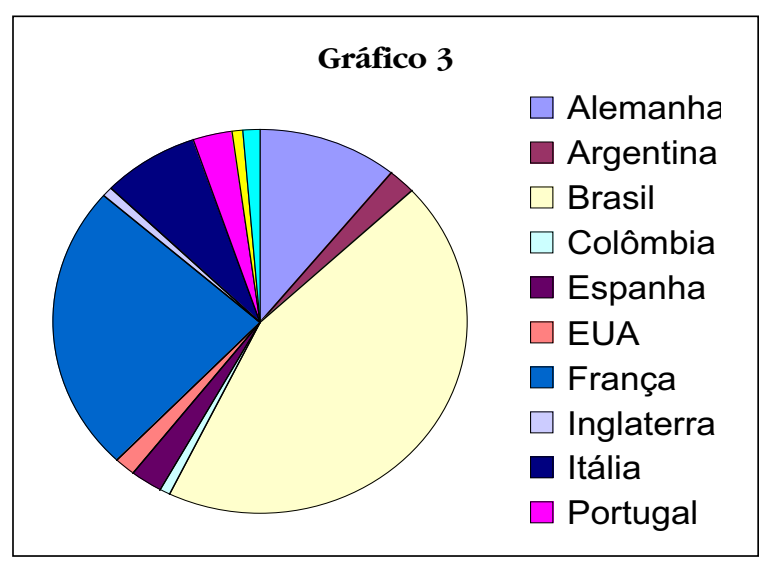

A codificação aprovada, que restringiu o pátrio poder (por meio de vários artigos individualistas, como a maioridade plena dos filhos a partir dos 21 anos, entre outros), foi tida como influenciada pelo código civil alemão (sobretudo pela intervenção marcante de Rui Barbosa no processo de discussão parlamentar da reforma do código). Contudo, temos várias indicações de que a alusão ao código alemão pode ter ocorrido como forma de dissimulação (ou discordância) das influências da codificação francesa, uma vez que estas encontravam, historicamente, muitas resistências políticas, ideológicas e afetivas na formação social brasileira (e portuguesa) para sua aceitação, dadas as suas implicações com o processo revolucionário. A julgar pela lista de obras sobre direito civil adquiridas pelo então senador Rui Barbosa, podemos afirmar que, ele sim, foi influenciado pelo código civil e pelo pensamento jurídico alemão, como mostram o Quadro 4 e o Gráfico 4.

Quadro 4

Obras de Direito Civil do Acervo da Biblioteca da Fundação Casa de Rui Barbosa

\begin{tabular}{lcc}
\hline País & Obras & $\%$ \\
\hline Alemanha & 95 & 52,77 \\
França & 50 & 27,77 \\
Itália & 32 & 17,77 \\
Outros & 3 & 1,66 \\
Total & 180 & 100 \\
\hline
\end{tabular}

Fonte: Catálogo Bibliográfico da Biblioteca da Fundação Casa de Rui Barbosa.

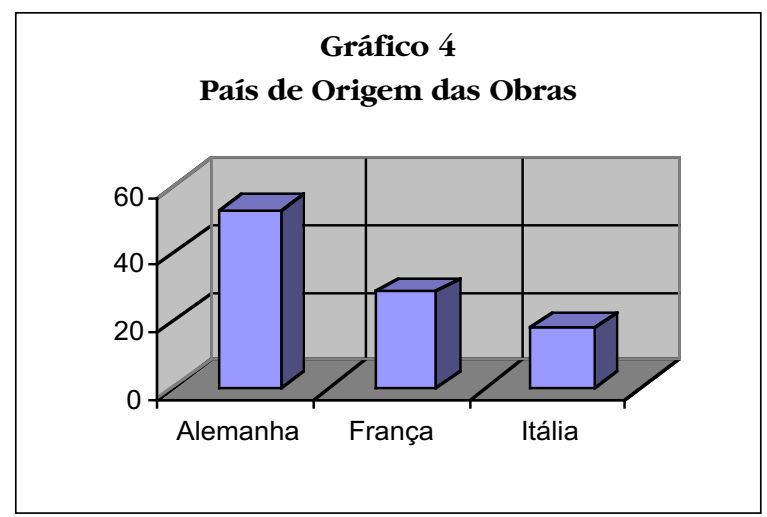

Supomos, portanto, que o atual direito de família no Brasil apresenta um quadro de influências múltiplas, embora haja uma evidente presença da literatura jurídica oriunda da França, conforme pode ser observado no Quadro 3. 
Mas, se procedermos a um levantamento da origem das obras disponíveis na biblioteca do Instituto dos Advogados Brasileiros (IAB), observamos, igualmente, a forte influência francesa em termos da circulação de idéias e de livros (Quadro 5 e Gráfico 5).

Quadro 5

Obras de Direito Civil do Acervo da Biblioteca do Instituto dos Advogados Brasileiros (IAB)

\begin{tabular}{lcc}
\hline País & Obras & $\%$ \\
\hline Brasil & 23 & 20,53 \\
França & 66 & 58,92 \\
Itália & 20 & 17,85 \\
Outros & 3 & 2,67 \\
Total & 112 & 100 \\
\hline
\end{tabular}

Fonte: Catálogo Bibliográfico da Biblioteca do IAB.

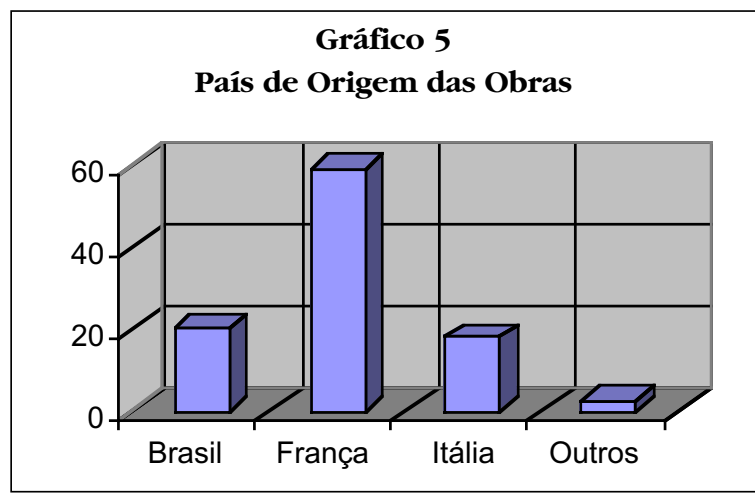

Igualmente significativa é a presença maciça de volumes de códigos civis comentados na biblioteca do IAB. Aqui, também, percebe-se a presença soberana da produção de origem francesa (Quadro 6 e Gráfico 6).

\section{Quadro 6}

Códigos Comentados no Acervo da Biblioteca do Instituto dos Advogados Brasileiros (IAB)

\begin{tabular}{lcc}
\hline País & Número de códigos & $\%$ \\
\hline França & 109 & 42,08 \\
Itália & 39 & 15,05 \\
Brasil & 34 & 13,12 \\
Portugal & 34 & 13,12 \\
Argentina & 14 & 5,4 \\
Espanha & 9 & 3,47 \\
Chile & 8 & 3,08 \\
Outros & 12 & 4,63 \\
Total & 259 & 100
\end{tabular}

Fonte: Catálogo Bibliográfico da Biblioteca do IAB.

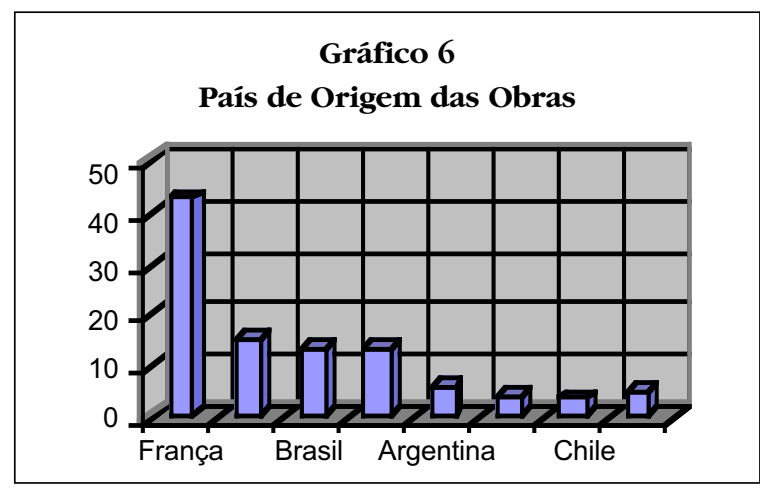

Criado em 1843, o IAB inaugurou sua biblioteca em 1896 (Lira, 1995). Sublinhe-se que se trata de uma biblioteca cujo acervo é assegurado exclusivamente por doações de juristas sócios do Instituto.

Mais interessante é observarmos, contudo, a completa ausência de obras oriundas da Alemanha, país que supostamente teria influenciado nosso Direito Civil. A aludida influência do código civil alemão sobre as leis civis brasileiras, se em alguma medida ocorreu, foi em função da exaustiva participação do senador Rui Barbosa, este sim, germanófilo, nas discussões da Comissão Especial do Senado sobre a redação do projeto da Câmara dos Deputados. ${ }^{9}$

\section{O pátrio poder no Brasil: hierarquia e obediência}

De um ponto de vista mais abrangente, estamos tratando das relações entre Igreja, Estado e Sociedade. A luta da Igreja para interferir na autoridade do paterfamilis data de muitos séculos. Embora seu projeto civilizatório e disciplinar em torno da instituição familiar tenha sido decisivamente implementado a partir do Concílio de Trento (Bossy, 1990), no bojo da reforma religiosa católica, o Concílio de Latrão (1215) representa o primeiro marco da ingerência da Igreja na autoridade das famílias (Lebrun, 1993). O casamento tornou-se um sacramento, sob o dogma da indissolubilidade dos laços matrimoniais. E, o que é mais importante, o consentimento dos noivos (por suposto, livre) abriu caminho para o fortalecimento do indivíduo diante da família, enfraquecendo a autoridade do pai e 
seus substitutos legais. Este não mais decide e acerta sozinho os casamentos. Ao mesmo tempo, não podemos deixar de sublinhar a arguta observação de François Lebrun, na abertura do seu texto "As reformas: devoções comunitárias e piedade pessoal" (Lebrun, 1991, p. 71), acerca da divisão do Cristianismo entre duas tendências aparentemente inconciliáveis. "É ao mesmo tempo uma religião eminentemente pessoal, que chama cada indivíduo à conversão, à fé e à salvação [...] e uma religião coletiva, apoiada numa Igreja." De um lado, a forte presença do Cristianismo, que marca decisivamente a Península Ibérica, cunhando histórica e ideologicamente uma cultura holística, patriarcal e francamente mi-sógina. De outro, identificamos vários passos na construção de uma dada idéia de indivíduo, que convive paradoxalmente com uma visão holista, notadamente a partir da filosofia tomista (Morse, 1988). ${ }^{10}$

Os tempos modernos, a partir, sobretudo, da virada do século XVIII para o XIX, marcam a elaboração de uma ideologia secular, que cimenta a sociedade e molda o Estado, substituindo a liturgia do pensamento religioso. Nas duas formações sociais em foco (Portugal e Brasil) este processo apresenta especificidades e ambigüidades que devem ser sublinhadas.

Temos, portanto, um universo patriarcal onde o paterfamilis era investido de autoridade e responsabilidade sobre todos os membros de sua casa, inclusive os empregados (Graham, 1992). Dependia de cada um prestar a obediência devida de acordo com o seu lugar - fosse como esposa ou como filho, como agregados ou escravos, como manda uma ordem fortemente hierarquizada.

A extensão do poder do chefe da família atingia um raio muito grande. Ele administrava legalmente as propriedades, os bens da família, tanto da esposa quanto dos filhos ainda solteiros, e concedia ou negava permissão para os filhos ou mesmo para uma filha viúva casar novamente. O casamento de seus subalternos, sobretudo de suas criadas, dependia de seu consentimento e sua interferência. A autoridade masculina estendia-se a todos os membros da casa. De acordo com as Ordenaçôes, o chefe de família tinha o direito de castigar fisicamente a sua mulher, os seus filhos, os seus criados e seus escravos. Todos sujeitavam-se à autoridade do senhor. Eram, também, objetos implícitos de sua proteção. O pátrio poder alcançava, portanto, todos os que moravam ou trabalhavam na mesma casa. Ao mesmo tempo, o casamento era considerado um sacramento, cuja administração e autoridade jurisdicional pertenciam à Igreja e eram regidas pelo Direito Canônico.

As idéias de casa e de família afetavam profundamente a natureza da política (Graham, 1997). Constituíam-se em unidades básicas da ordem política, e mostravam-se particularmente resistentes à mudança. O pai exercia autoridade legal sobre todos; podia até, legalmente, encarcerar filhos de qualquer idade que vivessem com ele. Pelas Ordenações do Reino, a emancipação dos filhos ocorria aos 25 anos. Entretanto, "[...] a lei considerava a propriedade dos filhos vivendo com a família, independente de sua idade, como pertencente ao pai" (p. 34). O termo pai de família (paterfamilis) implicava, além de cuidado (proteção), autoridade (obediência). Todavia, filhas e filhos solteiros permaneciam sob o jugo do pátrio poder para além dos 25 anos, sobretudo se morassem na casa paterna.

A extensão (cultural e política) do pátrio poder no Brasil afetou o encaminhamento de políticas públicas para a educação e a assistência social. Reside aí, no nosso entender, a explicação para a ineficácia da intervenção do Estado neste setor, mesmo quando enfocamos conjunturas históricas em que a presença do Estado é forte (o Estado Novo ou a recente ditadura militar), quando a legitimidade da ação estatal não podia ser questionada. Diferentemente da Inglaterra (e suas colônias), onde a caridade e a assistência à pobreza foram assumidas pelo Estado ( Poor Law, desde o período elizabetano), em Portugal (e no Brasil) estas práticas ficaram restritas à esfera da Igreja, e à caridade por ela instituída (as Santas Casas de Misericórdia). Os cuidados em relação a crianças e velhos têm sido tratados como um problema da ordem privada (das famílias). É um problema do paterfamilis, de quem todos esperam proteção como contrapartida da obediência irrestrita.

Os limites de uma família iam além do pai, da mãe e dos filhos. A proteção em troca de lealdade, 
imposta pelos vínculos familiares, estendia-se primeiramente a uma ampla gama de relacionamentos consangüíneos e por meios de casamentos. As relações sociais eram orientadas pelo paradigma familiar, que mesclava em seu interior força e benevolência. A falta de obediência ou lealdade deixava o indivíduo exposto à exploração de outros. Nas famílias, a ameaça de punição e a promessa de benevolência descreviam as vidas de esposas e filhos, escravos, agregados, pequenos proprietários, pequenos comerciantes e outros seguidores do senhor. Esta autoridade também atingia as relações de poder, principalmente as políticas. É esta autoridade do paterfamilis que o código civil veio limitar.

No Código Civil Brasileiro, a emancipação dos filhos e filhas está prevista para 18 (parcial) e 21 anos (total). Várias restrições ao pátrio poder foram firmadas. Entretanto, o costume seguia definindo a permanência dos filhos na casa (viver sob o teto do pai) como dever de proteção e obediência ao pai. O casamento constitui-se, portanto, fator importantíssimo de ruptura com o pátrio poder, do ponto de vista da construção da idéia de indivíduo.

Durante todo o período em que se discutiu a reforma das leis civis no Brasil, a defesa ou a resistência ao casamento civil dividiram opiniões. Sobretudo, as forças do conservadorismo clerical e dos patriarcas retardaram o quanto puderam a transferência das mãos da Igreja para as do Estado de todo o registro civil, mormente em relação ao matrimônio. Isto porque, uma vez colocado em mãos civis, o casamento deixaria de ser um sacramento e passaria a ser considerado um contrato, como na maioria das sociedades modernas. Todo contrato, em termos jurídicos, prevê o distrato. Portanto, a questão da indissolubilidade do casamento e do divórcio infletiu a discussão.

Uma vez proclamada a República, sob a liderança de positivistas (dentre os quais alguns francamente anticlericais), a Lei do Casamento e do Registro Civil foi decretada pelo Governo Provisório em 1890, sendo seu mentor Rui Barbosa. Quando o novo projeto de código civil, encomendado a Clovis Bevilacqua nos últimos anos do século XIX, foi discutido, encontrou em Rui Barbosa um grande opositor, cuja atuação parlamentar retardou em muito a sua aprovação. San Tiago
Dantas (1949) interpreta a intervenção de Rui Barbosa, que primou pela crítica aos erros de linguagem do projeto redigido por Clovis Bevilacqua, como tendo sido uma estratégia política do então senador da recém-proclamada República para impedir que o código fosse aprovado apressadamente, pois acreditava que este deveria ser uma obra duradoura e cuidadosamente elaborada. De nossa parte, tendemos a acentuar as discordâncias ideológicas e afetivas de Rui Barbosa com o individualismo presente no projeto (sob influência do ideário jurídico francês).

É bom lembrar que a decretação da Lei do Casamento e do Registro Civil (assim como a decretação do Código Penal de 1890), antes da Constituição (1891) — esta de corte liberal — teve uma intenção antecipatória, para garantir um suporte legal-institucional autoritário e repressivo às tecnologias de controle social. A institucionalização da ordem republicana no Brasil implicou, como era de se esperar, a separação da Igreja do Estado. Portanto, o casamento civil seria, de uma forma ou de outra, instituído. A lei de 1890 (Decreto n. 181) viabilizou o inevitável e não previu o divórcio, mantendo-se a indissolubilidade do casamento até 1977.

\section{Conclusão}

Para concluir, queremos retomar a reflexão sobre a inoperância das políticas públicas relativas ao atendimento de crianças e adolescentes no Brasil.

Como dissemos, com o Código Civil Brasileiro o pátrio poder sofreu, na letra da lei, uma restrição. Mas a extensão da obediência ao pai conferida pelo costume e pela prática política seguiu dando suporte político e ideológico a uma autoridade paterna plenipotente. Estamos lidando com uma figura paterna que dificulta a identificação de limites impostos pela lei, no sentido jurídico, mas também no sentido psicanalítico. A idéia de que o atendimento aos desvalidos (velhos, crianças abandonadas ou desassistidas e loucos) deveria ser feito por meio da montagem de uma estrutura institucional estatal acompanhou a modernização do país na virada do século XIX para o XX. No entanto, a 
permanência do poder do chefe de família atuou produzindo efeitos ideológicos que dificultaram o processo de legitimação das políticas públicas no setor. O sucesso das políticas públicas neste campo (realizadas por instituições governamentais ou nãogovernamentais) depende, em parte pelo menos, da construção de um arcabouço ideológico e afetivo de sustentação da função parental repousada numa autoridade capaz de substituir esta figura tão abrangente do paterfamilis.

Certamente os debates sobre os novos códigos (criminal e civil) constituíram-se num locus privilegiado em que a sociedade brasileira confrontou mudanças sociais - mas, afinal, nem tão radicais assim - associadas à modernização, à formação do Estado republicano, bem como aos sentidos cambiantes e diversificados da identidade nacional num período de transformações econômico-sociais e turbulências culturais.

\section{NOTAS}

1 Sobre a relação centro/periferia, trabalhamos com Carlo Ginzburg (1989), que se fundamenta em Bakthin (1987). No Brasil, encontramos a mesma abordagem em Antonio Candido (1993) e Roberto Schwarz (1977 e 1990).

2 PascoalJosé de Mello Freire, Direito público de Portugal, Seção de Reservados da Biblioteca Nacional de Lisboa, COD. 8.527; e Ensaio de código criminal a que mandou proceder a Rainba D. Maria I, Lisboa, Typographia Maiguense, 1823 (Seção de Obras Raras da Biblioteca Nacional do Rio de Janeiro)

3 Ver, do mesmo autor, Projecto de hum novo Regimento para o Sancto Officio, Seção de Reservados da Biblioteca Nacional de Lisboa, COD. 92.

4 No texto legislado, apenas. Tais poderes tão absolutizados têm implicado a ausência ou degradação da figura do pai (no sentido psicanalítico) na formação históricoideológica brasileira, com efeitos no processo de constituição identitária (Cerqueira Filho, 1993).

5 Referimo-nos a Instituiçôes políticas brasileiras, de Oliveira Vianna (1974), que constitui ainda fonte de referência fundamental destes estudos.

6 Trabalhamos com o livro de António Luís de Seabra (Visconde), Duas palavras sobre o casamento, publicado em 1866 em desagravo às acusações de anticlerical que vinha recebendo desde a redação do projeto de código civil português.

7 Sublinhe-se a importância dos desdobramentos de estudos com a orientação foucaultiana através de grupos interdisciplinares de pesquisa. No campo da história social, destaque-se o trabalho de Arlette Farge, em coautoria com o próprio Foucault (Foucault e Farge, 1982).

8 Trabalhamos com a obra de Anthoine de Saint-Joseph (1856), Concordance entre les codes civils étrangers et le code napoléon.

9 O parecer de Rui Barbosa foi publicado em 1902 sob o título Projecto de Código Civil Brazileiro — Trabalhos da Comissão Especial do Senado-Parecer do senador Ruy Barbosa sobre a redacção do projecto da Camara dos Deputados, 2 vols., Rio de Janeiro, Imprensa Nacional, 1902.

10 Trata-se de uma concepção do "indivíduo" e de "bem individual" como participante de um todo, em que o "bem comum" não pode ser substituído pelo ideal pessoal.

\section{BIBLIOGRAFIA}

ARIÈS, Philippe. (1978), História social da criança e da família. Rio de Janeiro, Zahar Editores.

BAKTHIN, M. (1987), A cultura popular na Idade Média e no Renascimento. São Paulo, Hucitec.

BOSSY, John. (1990), A cristandade ocidental 14001700. Lisboa, Edições 70.

BURGUIÈRE, André e LEBRUN, François. (1998), "As mil e uma famílias da Europa", in BURGUIÈRE, André e SEGALEN, Martine et al. (orgs.), História da família, vols. 3 e 4, Lisboa, Terramar, pp. 15-82.

BURGUIÈRE, André e SEGALEN, Martine et al.(orgs.). (1998), História da família, Lisboa, Terramar.

CANDIDO, Antônio. (1993), "A dialética da malandragem”, in A. Candido, O discurso e a cidade, São Paulo, Duas Cidades, pp. 19-54.

CERQUEIRA FILHO, Gisálio. (1993), Ideologia do favor e ignorância simbólica da lei. Rio de Janeiro, Imprensa do Estado do Rio de Janeiro.

CERQUEIRA FILHO, Gisálio e NEDER, Gizlene. (1997), Emoção e política: (a)ventura e imaginação sociológica para o novo milênio. Porto Alegre, S.A. Fabris Editor.

DANTAS, San Tiago. (1949), "Rui Barbosa e o Código Civil", in San Tiago Dantas, Dois momentos de Rui Barbosa, Rio de Janeiro, Casa de Rui Barbosa.

FAORO, Raymundo. (1975), Os donos do poder: formação do patronato político brasileiro, 2 vols. Porto Alegre/São Paulo, Editora Globo/Editora da Universidade de São Paulo. 
(1994), Existe um pensamento politico brasileiro? São Paulo, Ática.

FOUCAULT, Michel. (1978), Vigiar e punir. Nascimento da prisão. Petrópolis, Vozes, 1978.

FOUCAULT, Michel e FARGE, Arlette. (1982), Le désordre des familles. Lettres de cachet des Archives de la Bastile. Paris, Gallimard.

GINZBURG, Carlo. (1989), "A história da arte italiana", in C. Ginzburg, A micro-bistória e outros ensaios, Lisboa, Difel, pp. 5-118.

(1991), Mitos, emblemas, sinais: morfologia e história. São Paulo, Companhia das Letras.

GRAHAM, Richard. (1997), Clientelismo e politica no Brasil do século XIX. Rio de Janeiro, Ed. da UFRJ.

GRAHAM, Sandra. (1992), Proteção e obediência: criadas e seus patrões no Rio de Janeiro, 18601910. São Paulo, Companhia das Letras.

HERCULANO, Alexandre. (1866), "O casamento civil", in A. Herculano, Duas palavras sobre o casamento, Lisboa, Imprensa Nacional.

LEBRUN, François. (1991), "As reformas: devoções comunitárias e piedade pessoal", in Philippe Ariès e Roger Chartier (orgs.), História da vida privada, vol. 3, São Paulo, Companhia das Letras.

(1993), La vie conjugale sous l'Ancien Régime. Paris, Armand Collin.

LEGENDRE, Pierre. (1983), O amor do censor: ensaio sobre a ordem dogmática. Rio de Janeiro, Forense-Universitária.

(1988), Le dossier occidental de la parenté. Paris, Fayard.

(1992), Les enfants do texte: étude sur la fonction parentale des États. Paris, Fayard.

LIRA, Ricardo-Cesar Pereira (org.). (1995), História dos 150 anos do Instituto dos Advogados Brasileiros. Rio de Janeiro, Destaque.

MELLO FREIRE, Pascoal José. (1823), Ensaio de código criminal a que mandou proceder a Rainha D. Maria I. Lisboa, Typographia Maiguense.

. (s/d.), Direito público de Portugal. Manuscrito. Seção de Reservados da Biblioteca Nacional de Lisboa. (s/d.), Projecto de hum novo regimento para o Sancto Officio. Manuscrito. Seção de Reservados da Biblioteca Nacional de Lisboa.

MORSE, Richard. (1988), Espelho de Próspero: cultura e idéias nas Américas. São Paulo, Companhia das Letras.

NEDER, Gizlene. (1994), “Ajustando o foco das lentes: um novo olhar sobre a organização das famílias no Brasil", in Silvio Kaloustian (org.), Família brasileira, São Paulo, Cortez/Unicef, pp. 26-47.

(1995), Discurso jurídico e ordem burguesa no Brasil. Porto Alegre, S.A. Fabris Editor.

. (1996), "Absolutismo e punição". Discursos Sediciosos: Crime, Direito e Sociedade, Rio de Janeiro, Relume Dumará/ICC, Ano I, 1: 191-206.

. (2000), Iluminismo jurídico-penal lusobrasileiro: obediência e submissão. Rio de Janeiro, Freitas Bastos/ICC.

NEVES, Guilherme Paulo Pereira das. (1998), E receberá mercê: a mesa da consciência e ordens, o clero secular e a sociedade no Brasil (18081828). Rio de Janeiro, Prêmio Arquivo Nacional.

OLIVEIRA VIANNA, Francisco José. (1974), Instituições políticas brasileiras, 2 vols. $3^{\mathrm{a}} \mathrm{ed}$., Rio de Janeiro, Record.

SAINT-JOSEPH, Anthoine. (1856), Concordance entre les codes civils étrangers et le code napoléon. 4 tomos. $2^{\text {a }}$ ed., Paris, Cotillon, Librairie du Conseil d'Etat.

SCHWARZ, Roberto. (1977), "As idéias fora do lugar", in R. Schwarz, Ao vencedor as batatas, São Paulo, Duas Cidades, pp. 13-28.

(1990), Um mestre na periferia do capitalismo: Machado de Assis. São Paulo, Duas Cidades.

SEABRA, Luis António de (Visconde). (1866), Duas palavras sobre o casamento. Lisboa, Imprensa Nacional.

SILVA, Nuno Espinosa Gomes da. (1985), História do Direito português. Lisboa, Fundação Calouste Gulbenkian.

VIVEIROS DE CASTRO, Francisco. (1897), Os delictos contra a bonra da mulher. $1^{\mathrm{a}}$ ed., Rio de Janeiro, Imprensa Nacional. 